Article

\title{
Discharge Coefficients for Sluice Gates Set in Weirs at Different Upstream Wall Inclinations
}

\author{
Agostino Lauria *, Francesco Calomino, Giancarlo Alfonsi and Antonino D'Ippolito \\ Fluid Dynamics Laboratory, Dipartimento di Ingegneria Civile, Università della Calabria, Via P. Bucci, Cubo 42b, \\ 87036 Rende, Italy; francesco.calomino@unical.it (F.C.); giancarlo.alfonsi@unical.it (G.A.); \\ antonino.dippolito@unical.it (A.D.) \\ * Correspondence: agostino.lauria@unical.it
}

Received: 17 December 2019; Accepted: 13 January 2020; Published: 15 January 2020

\begin{abstract}
Laboratory experiments and numerical simulations are performed to measure discharge coefficients in the case of a gate located on the upstream wall of a weir for flood storage. The effect of the gate slope and the side contraction have been taken into account. The study was first performed experimentally, when three series of tests were carried out with (and without) a broad crested weir located under the gate, at different values of the inclination angle of the weir upstream wall, and at different values of the shape ratio and the relative opening. In order to provide useful suggestions for those involved in sluice gate construction and management, three equations were obtained based on multiple regression, relating the discharge coefficient to different parameters that characterize the phenomenon at hand, separating the case when the broad-crested weir was present. Then numerical simulations were executed by means of the Reynolds-averaged Navier-Stokes (RANS) equations with the $k-\varepsilon$ turbulence closure model and in conjunction with the volume of fluid (VOF) method, to validate the numerical results against the experimental and to possibly investigate phenomena not caught by the experimental measurements. Simulated discharges were very close to the observed ones showing that the proposed three-dimensional numerical procedure is a favorable option to correctly reproduce the phenomenon.
\end{abstract}

Keywords: weir; sluice gate; discharge coefficients; laboratory experiments; numerical simulations

\section{Introduction}

Sluice gates on the upstream walls of weirs represent one of the most efficient structural devices for river flood control and active defense from flooding. Weirs are usually placed transversely to the riverbed, which causes a backwater effect, thus allowing the storage of part of the flood volume in natural areas of the basin. In these cases, the river flow may be regulated by an orifice until the water level reaches the maximum allowed value, where an overflow structure is located.

Even though these devices are widely used, their hydraulics are still not completely understood. The most common problem concerns sluice gates that are set in a channel of the same width without considering the lateral contraction. This is significant in the case presented here.

In the literature many works can be found about planar sluice gates, both vertical and sloping, of which [1,2] give extensive reviews. In [1] the case of sluice gates having the angle between their plane and the horizontal plane greater than $90^{\circ}$ is reported, and in that case, the discharge coefficient decreased as the angle increased. In [3] the case of sluice gates having the angle between their plane and the horizontal plane less than or equal to $90^{\circ}$ was reported, showing that the recirculation is less important when this angle is small, so that the discharge coefficient decreases as the angle increases. 
The values of the discharge coefficients versus the relative gate opening $a / h$ (where $a$ is the gate opening and $h$ is the upstream water level) obtained by [3-6] show that these values range between 0.64 and 0.48 and decrease with $a / h$.

The underflow of a sluice gate, when its width is equal to the flume width, presents the following characteristics $[2,3,5]$ :

1. two vertical vortices are found at the upstream sides of the sluice gate, interfering with the flow;

2. a recirculation zone is present on the upper part of the flow upstream from the sluice gate, influencing the contraction of the effluent vein and consequently the discharge coefficient.

The problem can be treated by evaluation of the discharge coefficient $C_{\mathrm{d}}$, given by:

$$
C_{\mathrm{d}}=\frac{Q}{a \cdot b \cdot \sqrt{2 g\left(h-C_{\mathrm{c}} a\right)}}
$$

where $Q$ is the discharge, $b$ is the gate width, and $g$ is the gravity acceleration. In Equation (1) inviscid liquid conditions are considered and $C_{\mathrm{d}}$ is given by:

$$
C_{\mathrm{d}}=\frac{C_{\mathrm{c}}}{\sqrt{1+C_{\mathrm{c}} \frac{a}{h}}}
$$

as shown also in [3].

When the liquid is inviscid and $b$ is much larger than $a, C_{c}$ is given, as shown in [2], by the Rayleigh equation:

$$
C_{\mathrm{c}}=\frac{\pi}{\pi+2}=0.61
$$

Nevertheless, since the liquid is not inviscid and $b$ can be not much larger than $a$, one can write:

$$
C_{\mathrm{d}}=\frac{Q}{a \cdot b \cdot \sqrt{2 g h}}
$$

by neglecting the free-stream depth $C_{\mathrm{c}} a$ and including the uncertainty related to it into $C_{\mathrm{d}}$ only. In this case one can avoid evaluating $C_{c}$, which on the other hand is not easy to identify by measurement of the effluent stream depth.

In the numerical field, among others, [7-9], researchers carried out numerical studies following the RANS approach. The proposed numerical tools were sufficiently advanced to calculate the contraction and the discharge coefficients, and the flow pressure distribution past a sluice gate. In particular in [9], volume of fluid (VOF)-based CFD analysis of 2-D open channel flow under a vertical sluice gate was performed. Overall, the comparison of numerical and experimental results revealed that the simulations associated with the turbulent closure model predicted the velocity fields and the free surface flow profile more accurately and faster than those that used the k- $\omega$ model. Authors of [10] developed linear and nonlinear two-equation models, to determine the discharge coefficient by using dimensional analysis and linear and nonlinear regression analysis, for both free and submerged flow conditions.

The hydraulics of the underflow of sluice gates set in weirs appears scarcely considered, even though the problem of side contraction of the vein should definitely change the results in terms of discharge coefficients.

In this work, the underflow of a sluice gate set into a weir is analyzed, and both the effects of gate slope and side contraction are considered. The results obtained by experimental tests confirmed that lateral contraction significantly affects the phenomenon, while numerical analysis confirmed this result and could show other similar aspects as well as providing a valuable tool for the calculation of discharge coefficients in a more extended range of relative openings. 


\section{Materials and Methods}

The scheme reported in Figure 1 shows that the weir was divided in two blocks, by means of two vertical planes with an opening of width $b$ between them. A sluice gate set on the upstream wall could be closed, leaving an orifice of height $a$ and width $b$, while $h$ represents the upstream head. To make the flow free from any downstream influence, we used a broad-crested weir of height $d$ at the bottom of the opening. The sluice gate had one sharp edge and the flow below it was free and completely aerated.

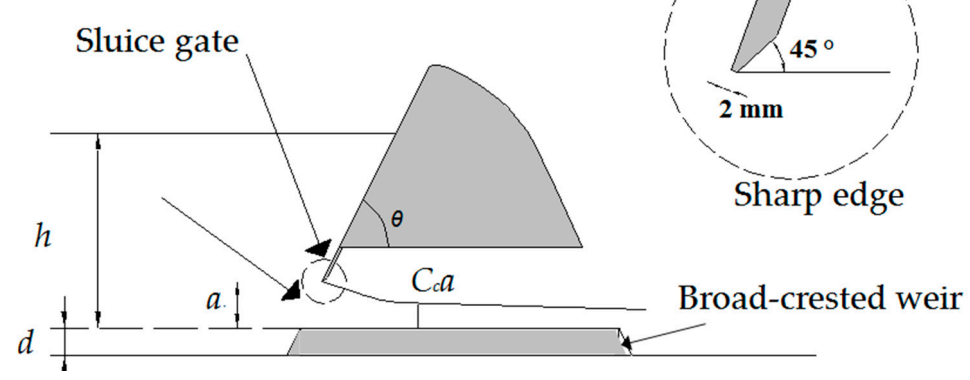

Figure 1. Definition sketch of sluice gate (vertical section along the middle of the gate opening of width b), with notation.

The study was first performed experimentally, when three series of tests were carried out with (and without) a broad-crested weir of height $d=20 \mathrm{~mm}$ located under the gate, at different values of the inclination angle $\theta$ of the weir upstream wall, that varied from $53.6^{\circ}$ to $90^{\circ}$, and at different values of the shape ratio $b / a$ and the relative opening $a / h$. Based on multiple regression, three expressions were found, relating the discharge coefficient with different parameters that characterized the phenomenon at hand.

Then, 27 numerical simulations were executed following the RANS approach to validate the numerical results against the experimental ones and to possibly investigate phenomena not caught by the experimental observation.

\subsection{Dimensional Analysis}

Considering the underflow of a sluice gate (Figure 1), we can assume a function $\mathrm{F}$ of the discharge $Q$ and the other geometrical variables $h, b$, and $a$, as defined above, the angle between the weir upstream wall and the horizontal plane $\theta$, the gravity acceleration $g$, the water density $\rho$, the kinematic viscosity $v$ the surface tension $\sigma$, and we can neglect the effect of the reservoir width, $B$, provided that it be sufficiently larger than $b$ and the effect of the broad-crested weir, namely:

$$
\mathrm{F}(Q, h, b, a, \theta, \mathrm{g}, \rho, v, \sigma)=0
$$

From the $\Pi$ theorem, by selecting $a, \rho$, and $\mathrm{g}$ as basic variables, one has:

$$
\Phi\left(\frac{Q}{a^{5 / 2} \cdot \sqrt{\mathrm{g}}}, \frac{b}{a}, \frac{h}{a}, \frac{a^{3 / 2} \cdot \sqrt{\mathrm{g}}}{v}, \frac{\rho \cdot g \cdot a^{2}}{\sigma}, \theta\right)=0
$$

where $\Phi$ is a generic function, the parameter $b / a$ is the shape ratio, $a / h$ is the relative opening, and

$$
\begin{aligned}
& \mathrm{Re}=\frac{a^{3 / 2} \cdot \sqrt{\mathrm{g}}}{v} \\
& \mathrm{We}=\frac{\rho \cdot \mathrm{g} \cdot a^{2}}{\sigma}
\end{aligned}
$$

are the Reynolds and Weber gate numbers, respectively. 
When the liquid is the same and the temperature is constant, in the experimental set-up, Re and We depend on each other and vary with the gate opening only, as shown in [11], so we have to remove one of the two.

One obtains:

$$
\Phi\left(\frac{Q}{a^{5 / 2} \cdot \sqrt{\mathrm{g}}}, \frac{b}{a}, \frac{h}{a}, \operatorname{Re}, \theta\right)=0
$$

and, taking into account Equation (4), one can write:

$$
C_{\mathrm{d}}=\Phi\left(\frac{a}{h}, \frac{b}{a}, \operatorname{Re}, \theta\right)
$$

Carrying out the tests in conditions where the viscosity and the surface tension do not affect the flow, $C_{\mathrm{d}}$ becomes a function of geometrical variables only:

$$
C_{\mathrm{d}}=\Phi\left(\frac{a}{h}, \frac{b}{a}, \theta\right)
$$

\subsection{Experimental Set-Up and Tests}

The experiments were conducted in a $1.20 \mathrm{~m}$ wide, $4.00 \mathrm{~m}$ long, and $0.25 \mathrm{~m}$ deep, horizontal, rectangular tank (Figure 2a,b) [12-14]. At its downstream end, a weir model $0.18 \mathrm{~m}$ high and $1.20 \mathrm{~m}$ wide was located. The orifice was created by dividing the weir in two parts in the middle by means of two vertical planes at a distance $b$ from each other, and using a sluice gate level with the upstream wall. A PVC gate $10 \mathrm{~mm}$ thick was used, of which the crest was sharp-edged (Figure 1). A small flume of the same width as the gate width $b$ was used downstream of the opening. For every series, three values of the gate widths $b=86,106$, and $142 \mathrm{~mm}$ were tested. The gate could be mounted with variable openings from the channel bottom. Three series of tests were carried out at different values of the weir upstream wall inclination angle $\theta$, that varied from $53.6^{\circ}$ to $90^{\circ}$. In the first series (Table 1 ) the angle $\theta$ was $63.4^{\circ}(1.11 \mathrm{rad})$ and the gate opening was varied from $a=20$ to $76 \mathrm{~mm}$. In these tests, a PVC broad-crested weir of height $d=20 \mathrm{~mm}$ was located under the gate. In the second series (Table 2$)$ three values of the weir angle $\theta=56.3^{\circ}(0.98 \mathrm{rad}), 63.4^{\circ}(1.11 \mathrm{rad})$, and $90^{\circ}(1.57 \mathrm{rad})$ were considered, with gate openings $a \geq 50 \mathrm{~mm}$. Also, in this case, the broad-crested weir was located under the gate. In the third series (Table 3$)$ three values of the angle $\theta=45^{\circ}(0.78 \mathrm{rad}), 63.4^{\circ}(1.11 \mathrm{rad})$, and $90^{\circ}$ (1.57 rad) were considered, and there were three values of the gate opening $a=50,60$ and $70 \mathrm{~mm}$. For the latter series the broad-crested weir was not present.

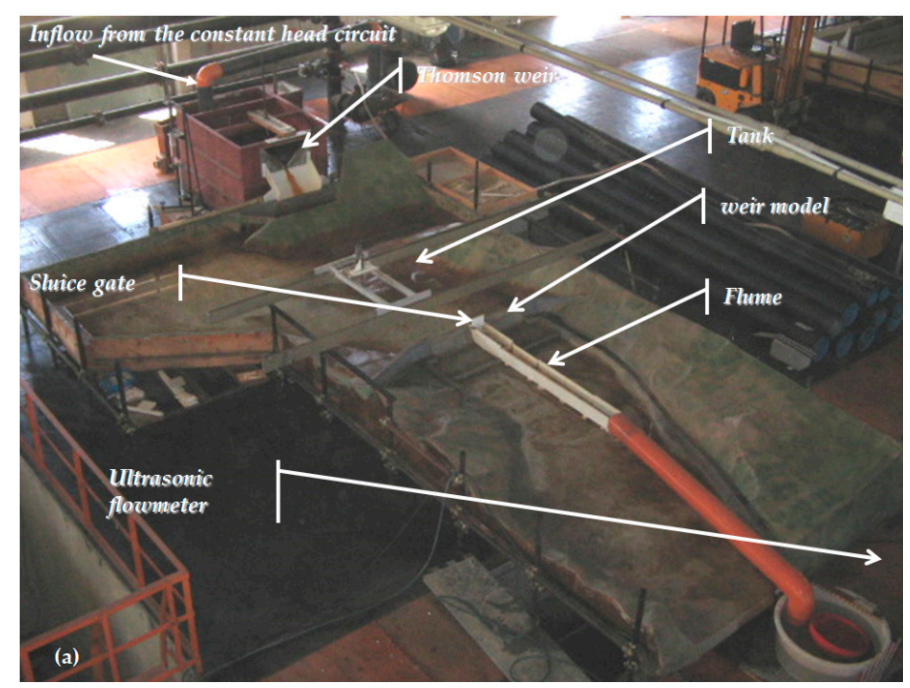

Figure 2. Cont. 


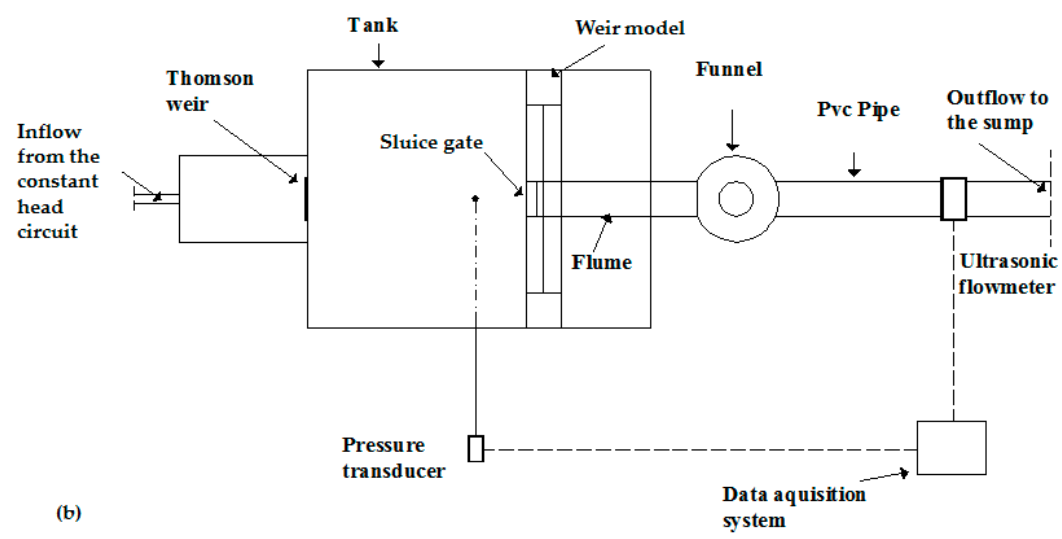

Figure 2. (a) Physical model (view from downstream) and (b) definition sketch, with notation.

Table 1. Experimental data Series 1.

\begin{tabular}{ccccccccc}
\hline Run & $\boldsymbol{\theta}\left({ }^{\circ}\right)$ & $\boldsymbol{a}(\mathbf{m m})$ & $\boldsymbol{b}(\mathbf{m m})$ & $\boldsymbol{h}(\mathbf{m m})$ & $\boldsymbol{Q}(\mathbf{L} / \mathbf{s})$ & $\boldsymbol{b} / \boldsymbol{a}$ & $\boldsymbol{a} / \boldsymbol{h}$ & $\boldsymbol{C}_{\mathbf{d}}$ \\
\hline 1 & 63.4 & 20 & 142 & $43.4 \div 116.4$ & $1.58 \div 2.74$ & 7.10 & $0.17 \div 0.46$ & $0.60 \div 0.64$ \\
2 & 63.4 & 24 & 86 & $40.7 \div 109.1$ & $1.02 \div 1.85$ & 3.55 & $0.22 \div 0.60$ & $0.55 \div 0.61$ \\
3 & 63.4 & 30 & 86 & $57.6 \div 140.9$ & $1.45 \div 2.53$ & 2.84 & $0.22 \div 0.53$ & $0.52 \div 0.58$ \\
4 & 63.4 & 30 & 106 & $52.6 \div 130.4$ & $1.62 \div 3.04$ & 3.55 & $0.23 \div 0.57$ & $0.50 \div 0.60$ \\
5 & 63.4 & 30 & 142 & $56.4 \div 151.4$ & $2.43 \div 4.44$ & 4.73 & $0.20 \div 0.53$ & $0.54 \div 0.61$ \\
6 & 63.4 & 37 & 106 & $64.9 \div 121.8$ & $2.15 \div 3.41$ & 2.84 & $0.31 \div 0.58$ & $0.48 \div 0.56$ \\
7 & 63.4 & 40 & 142 & $91.9 \div 131.4$ & $4.08 \div 5.03$ & 3.55 & $0.30 \div 0.44$ & $0.54 \div 0.55$ \\
8 & 63.4 & 50 & 86 & $89.0 \div 105.0$ & $2.73 \div 3.13$ & 1.72 & $0.48 \div 0.56$ & $0.48 \div 0.51$ \\
9 & 63.4 & 50 & 142 & $86.8 \div 128.8$ & $4.33 \div 6.08$ & 2.84 & $0.39 \div 0.58$ & $0.47 \div 0.54$ \\
10 & 63.4 & 53 & 106 & $90.5 \div 123.6$ & $3.45 \div 4.40$ & 2.00 & $0.43 \div 0.59$ & $0.46 \div 0.50$ \\
11 & 63.4 & 60 & 86 & $104.8 \div 136.9$ & $3.45 \div 4.25$ & 1.43 & $0.44 \div 0.57$ & $0.47 \div 0.50$ \\
12 & 63.4 & 60 & 142 & $100.9 \div 144.5$ & $5.65 \div 7.48$ & 2.37 & $0.42 \div 0.59$ & $0.47 \div 0.52$ \\
13 & 63.4 & 62 & 106 & $102.1 \div 142.6$ & $4.15 \div 5.46$ & 1.72 & $0.43 \div 0.61$ & $0.45 \div 0.50$ \\
14 & 63.4 & 74 & 106 & $122.8 \div 145.9$ & $5.55 \div 6.43$ & 1.43 & $0.51 \div 0.60$ & $0.46 \div 0.48$ \\
15 & 63.4 & 75 & 86 & $124.8 \div 140.5$ & $4.52 \div 5.02$ & 1.15 & $0.53 \div 0.60$ & $0.45 \div 0.47$ \\
\hline
\end{tabular}

Table 2. Experimental data Series 2.

\begin{tabular}{ccccccccc}
\hline Run & $\boldsymbol{\theta}\left(\boldsymbol{\circ}^{\circ}\right)$ & $\boldsymbol{a}(\mathbf{m m})$ & $\boldsymbol{b}(\mathbf{m m})$ & $\boldsymbol{h}(\mathbf{m m})$ & $\boldsymbol{Q}(\mathbf{L} / \mathbf{s})$ & $\boldsymbol{b} / \boldsymbol{a}$ & $\boldsymbol{a} / \boldsymbol{h}$ & $\boldsymbol{C}_{\mathbf{d}}$ \\
\hline 16 & 63.4 & 50 & 142 & $86.8 \div 128.0$ & $4.30 \div 6.10$ & 2.84 & $0.58 \div 0.39$ & $0.47 \div 0.54$ \\
17 & 63.4 & 60 & 142 & $100.9 \div 144.5$ & $5.60 \div 7.50$ & 2.37 & $0.59 \div 0.41$ & $0.47 \div 0.52$ \\
18 & 63.4 & 50 & 86 & $89.0 \div 104.8$ & $2.70 \div 3.50$ & 1.72 & $0.56 \div 0.48$ & $0.48 \div 0.51$ \\
19 & 63.4 & 60 & 86 & $104.8 \div 136.9$ & $3.50 \div 4.30$ & 1.43 & $0.57 \div 0.44$ & $0.47 \div 0.50$ \\
20 & 63.4 & 75 & 86 & $124.8 \div 140.5$ & $4.50 \div 5.00$ & 1.15 & $0.60 \div 0.53$ & $0.45 \div 0.47$ \\
21 & 63.4 & 53 & 106 & $90.5 \div 123.6$ & $3.50 \div 4.40$ & 2.00 & $0.59 \div 0.43$ & $0.46 \div 0.50$ \\
22 & 63.4 & 62 & 106 & $102.1 \div 142.6$ & $4.20 \div 5.50$ & 1.72 & $0.60 \div 0.43$ & $0.46 \div 0.50$ \\
23 & 63.4 & 74 & 106 & $122.8 \div 143.3$ & $5.60 \div 6.40$ & 1.43 & $0.60 \div 0.51$ & $0.46 \div 0.48$ \\
24 & 90.0 & 50 & 86 & $73.5 \div 97.0$ & $2.40 \div 3.20$ & 1.72 & $0.68 \div 0.51$ & $0.47 \div 0.53$ \\
25 & 90.0 & 60 & 86 & $98.2 \div 124.8$ & $3.50 \div 4.30$ & 1.43 & $0.61 \div 0.48$ & $0.49 \div 0.53$ \\
26 & 90.0 & 75 & 86 & $109.7 \div 129.1$ & $4.40 \div 5.10$ & 1.15 & $0.68 \div 0.58$ & $0.46 \div 0.50$ \\
27 & 90.0 & 53 & 106 & $91.1 \div 112.1$ & $3.80 \div 4.40$ & 2.00 & $0.58 \div 0.47$ & $0.50 \div 0.53$ \\
28 & 90.0 & 62 & 106 & $103.9 \div 124.5$ & $4.60 \div 5.40$ & 1.71 & $0.60 \div 0.50$ & $0.49 \div 0.52$ \\
29 & 90.0 & 74 & 106 & $108.4 \div 131.2$ & $5.60 \div 6.30$ & 1.43 & $0.68 \div 0.56$ & $0.40 \div 0.50$ \\
30 & 90.0 & 50 & 142 & $101.5 \div 123.9$ & $5.30 \div 6.40$ & 2.84 & $0.49 \div 0.40$ & $0.53 \div 0.57$ \\
31 & 90.0 & 60 & 142 & $109.6 \div 138.6$ & $6.20 \div 7.60$ & 2.37 & $0.55 \div 0.43$ & $0.50 \div 0.54$ \\
32 & 56.3 & 50 & 142 & $78.8 \div 155.0$ & $4.30 \div 6.60$ & 2.84 & $0.63 \div 0.32$ & $0.48 \div 0.53$ \\
33 & 56.3 & 60 & 142 & $90.0 \div 153.9$ & $5.20 \div 7.60$ & 2.37 & $0.67 \div 0.39$ & $0.46 \div 0.52$ \\
34 & 56.3 & 53 & 106 & $81.4 \div 125.9$ & $3.30 \div 4.50$ & 2.00 & $0.65 \div 0.42$ & $0.46 \div 0.51$ \\
35 & 56.3 & 62 & 106 & $93.9 \div 139.7$ & $4.00 \div 5.50$ & 1.71 & $0.66 \div 0.44$ & $0.45 \div 0.50$ \\
36 & 56.3 & 74 & 106 & $104.6 \div 143.8$ & $4.90 \div 6.50$ & 1.43 & $0.71 \div 0.51$ & $0.43 \div 0.49$ \\
37 & 56.3 & 50 & 86 & $72.0 \div 102.8$ & $2.30 \div 3.20$ & 1.72 & $0.69 \div 0.49$ & $0.44 \div 0.52$ \\
38 & 56.3 & 60 & 86 & $88.4 \div 136.5$ & $3.00 \div 4.30$ & 1.43 & $0.68 \div 0.44$ & $0.44 \div 0.51$ \\
39 & 56.3 & 75 & 86 & $100.8 \div 137.1$ & $3.90 \div 5.00$ & 1.15 & $0.74 \div 0.55$ & $0.43 \div 0.47$ \\
\hline
\end{tabular}


Table 3. Experimental data Series 3 (see also [15]).

\begin{tabular}{ccccccccc}
\hline Run & $\boldsymbol{\theta}\left(\mathbf{}^{\circ}\right)$ & $\boldsymbol{a}(\mathbf{m m})$ & $\boldsymbol{b}(\mathbf{m m})$ & $\boldsymbol{h}(\mathbf{m m})$ & $\boldsymbol{Q} \mathbf{( L / s )}$ & $\boldsymbol{b} / \boldsymbol{a}$ & $\boldsymbol{a} / \boldsymbol{h}$ & $\boldsymbol{C}_{\mathbf{d}}$ \\
\hline 40 & 90 & 50 & 142 & $74.9 \div 176.1$ & $3.30 \div 7.40$ & 2.84 & $0.67 \div 0.28$ & $0.39 \div 0.56$ \\
41 & 90 & 60 & 142 & $115.5 \div 148.6$ & $6.10 \div 7.70$ & 2.36 & $0.52 \div 0.40$ & $0.47 \div 0.53$ \\
42 & 90 & 70 & 142 & $87.7 \div 122.2$ & $4.80 \div 7.50$ & 2.03 & $0.80 \div 0.57$ & $0.37 \div 0.50$ \\
43 & 90 & 50 & 106 & $66.6 \div 142.0$ & $2.70 \div 4.90$ & 2.12 & $0.75 \div 0.35$ & $0.44 \div 0.55$ \\
44 & 90 & 60 & 106 & $79.3 \div 156.4$ & $3.00 \div 6.00$ & 1.76 & $0.76 \div 0.38$ & $0.38 \div 0.55$ \\
45 & 90 & 70 & 106 & $89.7 \div 180.1$ & $3.50 \div 7.60$ & 1.51 & $0.78 \div 0.39$ & $0.35 \div 0.54$ \\
46 & 90 & 50 & 86 & $65.9 \div 152.5$ & $2.40 \div 4.20$ & 1.72 & $0.76 \div 0.33$ & $0.49 \div 0.58$ \\
47 & 90 & 60 & 86 & $73.9 \div 151.5$ & $2.60 \div 4.80$ & 1.43 & $0.81 \div 0.40$ & $0.41 \div 0.54$ \\
48 & 90 & 70 & 86 & $87.4 \div 154$ & $3.10 \div 5.50$ & 1.23 & $0.80 \div 0.45$ & $0.40 \div 0.55$ \\
49 & 63.4 & 50 & 142 & $46.1 \div 144.06$ & $3.30 \div 6.30$ & 2.84 & $1.08 \div 0.35$ & $0.48 \div 0.54$ \\
50 & 63.4 & 60 & 142 & $99.9 \div 156.3$ & $5.00 \div 7.60$ & 2.36 & $0.60 \div 0.38$ & $0.42 \div 0.51$ \\
51 & 63.4 & 70 & 142 & $46.1 \div 128.8$ & $4.20 \div 7.40$ & 2.03 & $1.52 \div 0.54$ & $0.45 \div 0.47$ \\
52 & 63.4 & 50 & 106 & $76.5 \div 148.7$ & $2.80 \div 4.70$ & 2.12 & $0.65 \div 0.34$ & $0.43 \div 0.51$ \\
53 & 63.4 & 60 & 106 & $82.7 \div 147.5$ & $3.10 \div 5.50$ & 1.76 & $0.72 \div 0.41$ & $0.38 \div 0.50$ \\
54 & 63.4 & 70 & 106 & $92.1 \div 148.4$ & $3.50 \div 6.10$ & 1.51 & $0.76 \div 0.47$ & $0.36 \div 0.50$ \\
55 & 63.4 & 50 & 86 & $64.5 \div 131$ & $2.30 \div 3.60$ & 1.72 & $0.77 \div 0.38$ & $0.48 \div 0.52$ \\
56 & 63.4 & 60 & 86 & $80.7 \div 144.6$ & $2.60 \div 4.30$ & 1.43 & $0.74 \div 0.41$ & $0.39 \div 0.51$ \\
57 & 63.4 & 70 & 86 & $90.4 \div 152.8$ & $3.00 \div 5.10$ & 1.23 & $0.77 \div 0.46$ & $0.37 \div 0.49$ \\
58 & 45 & 50 & 142 & $62.1 \div 109$ & $3.00 \div 5.20$ & 2.84 & $0.80 \div 0.46$ & $0.38 \div 0.50$ \\
59 & 45 & 60 & 142 & $93.8 \div 141.5$ & $4.70 \div 7.20$ & 2.36 & $0.64 \div 0.42$ & $0.41 \div 0.50$ \\
60 & 45 & 70 & 142 & $85.7 \div 125.9$ & $4.30 \div 7.40$ & 2.03 & $0.82 \div 0.56$ & $0.33 \div 0.47$ \\
61 & 45 & 50 & 106 & $65.1 \div 117.3$ & $2.50 \div 4.10$ & 2.12 & $0.77 \div 0.43$ & $0.42 \div 0.51$ \\
62 & 45 & 60 & 106 & $75.7 \div 144.62$ & $2.90 \div 5.40$ & 1.76 & $0.79 \div 0.41$ & $0.38 \div 0.50$ \\
63 & 45 & 70 & 106 & $86.3 \div 154.6$ & $3.40 \div 6.30$ & 1.51 & $0.81 \div 0.45$ & $0.35 \div 0.48$ \\
64 & 45 & 50 & 86 & $66.1 \div 125.1$ & $2.50 \div 3.50$ & 1.72 & $0.76 \div 0.40$ & $0.50 \div 0.53$ \\
65 & 45 & 60 & 86 & $76.2 \div 136.0$ & $2.50 \div 4.20$ & 1.43 & $0.79 \div 0.44$ & $0.40 \div 0.50$ \\
66 & 45 & 70 & 86 & $86.9 \div 140.3$ & $2.90 \div 4.80$ & 1.23 & $0.81 \div 0.50$ & $0.37 \div 0.48$ \\
\hline
\end{tabular}

The flow was from the constant-head pipe circuit of the laboratory fed the tank. The discharge was measured by means of an ultrasonic flowmeter located on a PVC pipe downstream of the flume. A calibrated Thomson weir located upstream to the tank was used to check the ultrasonic flowmeter, when the flow was steady. During each test, the water level in the tank was recorded by means of a pressure transducer, with the tapping at $50 \mathrm{~cm}$ upstream from the orifice. A number of piezometric taps were in turn connected to the same pressure transducer [16], in order to get pressure measurements in 12 points of the tank. Once steady-state conditions were achieved, the free surface levels were measured by means of an electric point gauge with $\pm 0.5 \mathrm{~mm}$ reading accuracy, so allowing the control of the pressure transducer measurement. Both flow and free surface measurements were collected at a frequency of $50 \mathrm{~Hz}$. In Tables 1-3 the values of the discharge coefficient is calculated using Equation (4).

\subsection{Numerical Simulations}

By means of numerical simulations the 27 runs of the Series 3 (Table 3) were carried out (considering the maximum values of $h$ and $Q$ ) by solving the three-dimensional Reynolds-averaged Navier-Stokes (RANS) equations [17-19] in conservative form (the fluid is incompressible and viscous, Einstein summation convention applies to repeated indices, $i, j=1,2,3)$ :

$$
\begin{gathered}
\rho \frac{\partial \bar{u}_{i}}{\partial t}+\rho \bar{u}_{j} \frac{\partial \bar{u}_{i}}{\partial x_{j}}=-\frac{\partial \bar{p}}{\partial x_{i}}+\frac{\partial}{\partial x_{j}}\left(2 \mu \bar{s}_{i j}-\rho \overline{u_{i}^{\prime} u_{j}^{\prime}}\right) \\
\frac{\partial \bar{u}_{i}}{\partial x_{i}}=0
\end{gathered}
$$


where $\rho$ is the fluid density, $\mu$ the water dynamic viscosity, $\bar{p}$ the mean fluid pressure, $\bar{u}_{i}$ are the mean velocity components, $\bar{s}_{i j}$ is the mean strain-rate tensor:

$$
\bar{s}_{i j}=\frac{1}{2}\left(\frac{\partial \bar{u}_{i}}{\partial x_{j}}+\frac{\partial \bar{u}_{j}}{\partial x_{i}}\right)
$$

and the quantity $\tau_{i j}=-\rho \overline{u_{i}^{\prime} u_{j}^{\prime}}$ is the Reynolds-stress tensor. The Reynolds-stresses are components of a symmetric, second-order tensor, where the diagonal components are normal stresses, while the off-diagonal elements are shear stresses. The Reynolds averaging procedure introduces six new unknown quantities (the six independent components of $\tau_{i j}$ ) without providing additional equations. To close the system, the Boussinesq approximation has been used [20] and the eddy-viscosity has been expressed as a function of the turbulent kinetic energy $(k)$ and the energy-dissipation rate $(\varepsilon)$, leading to a two-equation turbulence model. In the present study, in order to establish a relationship between the Reynolds stresses and the mean flow field, the $k-\varepsilon$ model [21] has been used.

For the execution of the calculations, the Flow-3D [22-24] finite-volume computational code has been used. In this code, the free-surface condition is handled with the VOF (volume of fluid) [25] method, that has extensively proven to be able to accurately track a wave interface [26,27]. The VOF method has been already used by several authors [24,26,27], always giving satisfactory results. This technique locates and tracks the free surface flow. To each fluid phase (hereinafter air and water), an individual fraction of the volume is associated, so that the indicator function $\zeta$ can be expressed:

$$
\zeta(x, t)=\left\{\begin{array}{cc}
1 & \text { water } \\
0 & \text { air } \\
0<\zeta<1 & \text { free surface }
\end{array}\right.
$$

The two-phase flow can be assumed as a mixed fluid. Thus, the density and the dynamic viscosity can be defined:

$$
\begin{aligned}
& \rho=\zeta \rho_{1}+(1-\zeta) \rho_{2} \\
& \mu=\zeta \mu_{1}+(1-\zeta) \mu_{2}
\end{aligned}
$$

in which the subscripts 1 and 2 indicate the two selected fluids (1 representing water and 2, air) and the volume-fraction function can be calculated by solving an advection equation for the velocity field:

$$
\frac{\partial \zeta}{\partial t}+\nabla \cdot(\zeta V)=0
$$

The meshing technique does not induce mesh distortion during transients (a multi-block meshing technique can be also used to provide higher resolutions in the calculations, where needed). The time-marching procedure includes three main steps: (1) evaluation of the velocity in each cell using the initial conditions (or previous-time-step values) for the advective pressures (and/or other accelerations), on the basis of appropriate explicit approximations of the governing equations; (2) adjustment of the pressure in each cell to satisfy the continuity equation; and (3) updating of the fluid free surface to give the new fluid configuration based on the volume-of-fluid value in each cell. In the present calculations, the available solution scheme based on the generalized minimal residual (GMRES) method has been used. The fluid properties used in the simulations are reported in Table 4.

Table 4. Fluid properties used in the simulations.

\begin{tabular}{cccc}
\hline Air Density & Water Density & Air Kinematic Viscosity & Water Kinematic Viscosity \\
\hline $1.225 \mathrm{~kg} / \mathrm{m}^{3}$ & $1000 \mathrm{~kg} / \mathrm{m}^{3}$ & $1.48 \times 10^{-5} \mathrm{~m}^{2} / \mathrm{s}$ & $1.0 \times 10^{-6} \mathrm{~m}^{2} / \mathrm{s}$ \\
\hline
\end{tabular}


As for the numerical channel, a rectangular tank $0.496 \mathrm{~m}$ long and $0.400 \mathrm{~m}$ wide and a rectangular horizontal channel $0.300 \mathrm{~m}$ long has been considered. The computational domain extends $0.796 \mathrm{~m} \times$ $0.400 \mathrm{~m} \times 0.300 \mathrm{~m}$ along the $\mathrm{x}$ (streamwise), $\mathrm{y}$ (spanwise), and $\mathrm{z}$ (vertical) directions, respectively.

The origin of the coordinate system $(x, y, z)$ is located at the lower-left corner of the computational domain, as shown in Figure 3a,b.

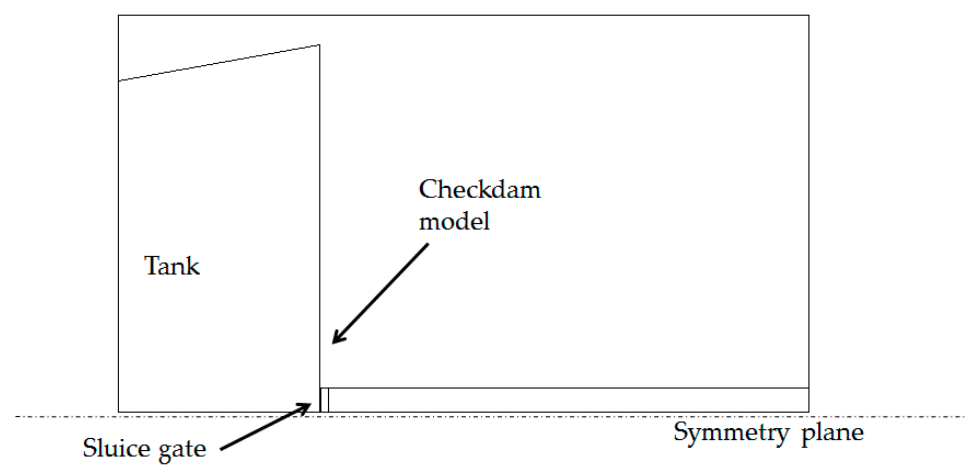

(a)

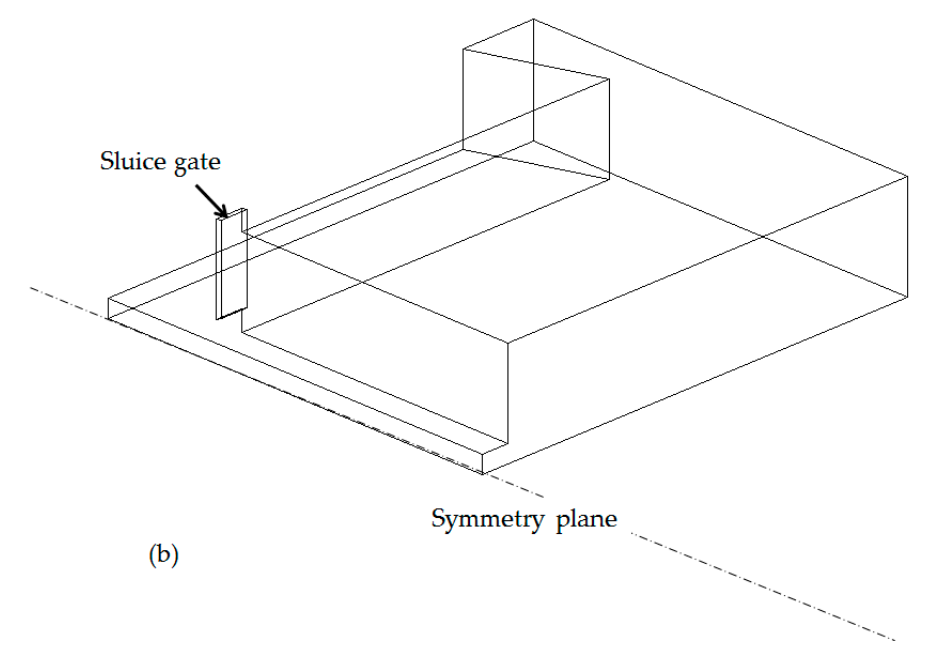

Figure 3. Computational domain: (a) plan view and (b) 3D view from downstream.

As for grid refinement, the unstructured computational mesh was refined through different steps, up to the point in which the comparisons of the computed results with those obtained by other authors became satisfactory. The final configuration of the computational grid is reported in Table 5.

Table 5. Characteristic parameters of the computational grid.

\begin{tabular}{cccccc}
\hline $\mathbf{N x}$ & $\mathbf{N y}$ & $\mathbf{N z}$ & $\Delta x_{- \text {min }}(m)$ & $\Delta y_{\_ \text {min }}(m)$ & $\Delta z_{\_ \text {min }}(m)$ \\
\hline 124 & 100 & 150 & 0.002 & 0.002 & 0.002 \\
\hline
\end{tabular}

The boundary conditions used for the computational domain are as follows: the no-slip (and zero wall-normal velocity) condition was imposed on the $x-y$ bottom plane at the geometry external surface. To reduce the computational cost, the symmetry condition was imposed on the $x-z$ left boundary plane and on the top of computational domain, on the $y-z$ end-plane of the computing domain outflow conditions had been set, while the free-surface condition held at the fluid surface. On the $y-z$ inlet plane, constant fluid depth was imposed, equal to that observed in the companion experimental test. 
An initial condition of constant depth, equal to that measured experimentally and equal to that imposed at $y-z$ plane, was imposed in the portion of domain upstream of the gate. The fluid moved with an instantaneous opening of the gate at $t=0$.

A specially-assembled computing system was used for the simulations, that included 2 Intel Xeon 5660 exa-core multi-core processors (a total of 12 CPUs available), a maximum of 48 GB of RAM, and up to 1.8 TB of mass memory [28].

The simulations were executed using 16 processors. For parallel computing, the technique of the domain decomposition was adopted to split the geometry and the associated fields into segments. In this study, the "simple geometric decomposition" technique was used, in which the domain was broken into segments by direction. The elapsed computational time was about 6 hours of CPU time for each simulation.

The stability of the solution procedure was ensured by utilizing an adaptive time step with an initial value of $1 \times 10^{-6} \mathrm{~s}$, in conjunction with a mean Courant-Friedrichs-Lewy (CFL) number limit of 0.5 .

\section{Results and Discussion}

\section{Experimental Results}

Figure 4 shows the values of the discharge coefficient as a function of the relative opening $a / h$ with a weir inclination angle $\theta=63.4^{\circ}$ and with the aspect ratio $b / a$ in the range 1.15-7.10 (Table 1).

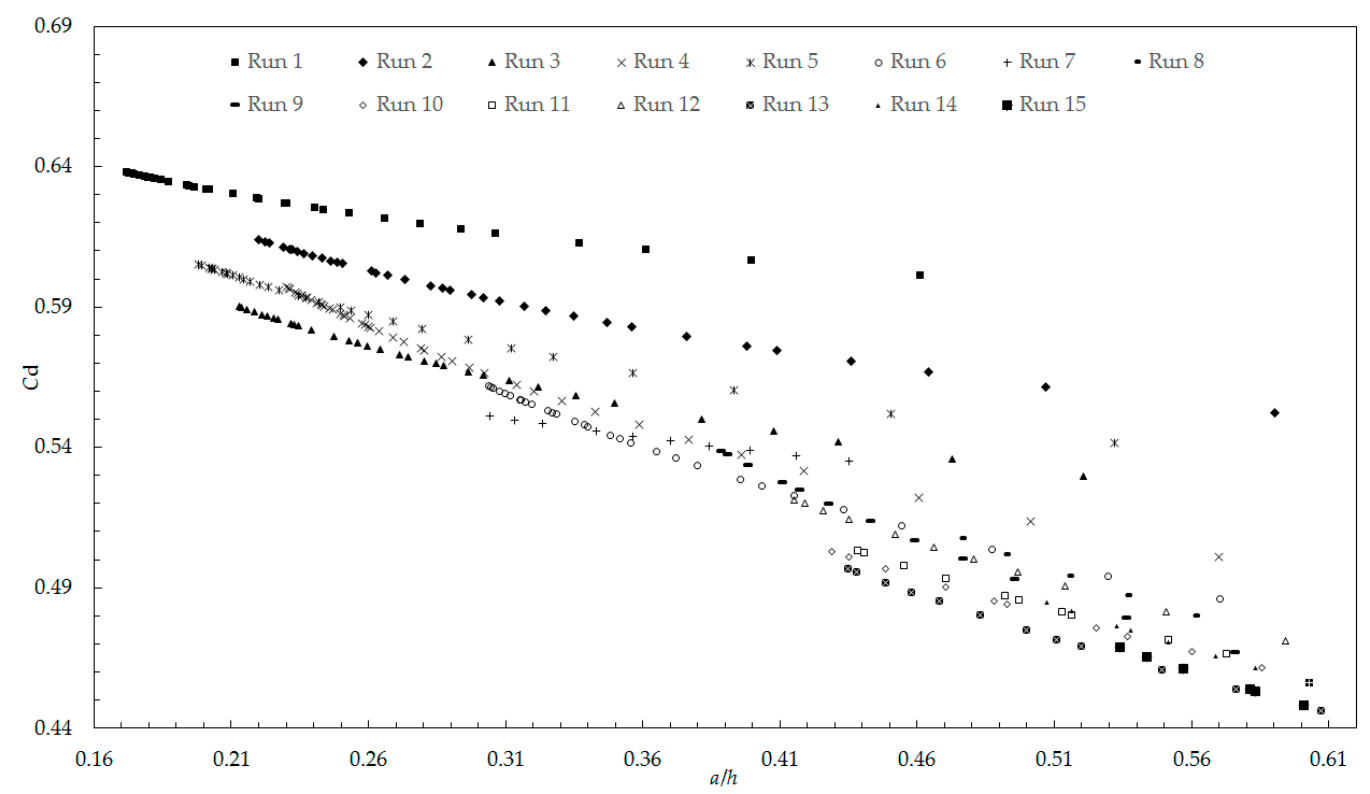

Figure 4. Discharge coefficients $\left(C_{\mathrm{d}}\right)$ versus $a / h$, Series 1 .

By following the method proposed by [5], of analyzing the minimum value of the discharge coefficient, $\left(C_{\mathrm{d}, \mathrm{min}}\right)$, as a function of the Reynolds number, it was possible to identify a threshold value of this number, below which the viscosity substantially influenced the phenomenon.

The trend of the experimental data ( $\operatorname{Re}$ and $C_{d, \min }$ ), reported in Figure 5, showed that for values of $\operatorname{Re} \leq 2.3 \times 10^{4}$ the discharge coefficient varied rapidly, while for larger values it remained almost constant. Therefore, the results obtained highlight that, for $a \geq 4.0$, We $>220$, and $\operatorname{Re}>2.3 \times 10^{4}$, it is possible to neglect the effects of viscosity and surface tension, in accordance with what is reported in the literature [1,29]. 


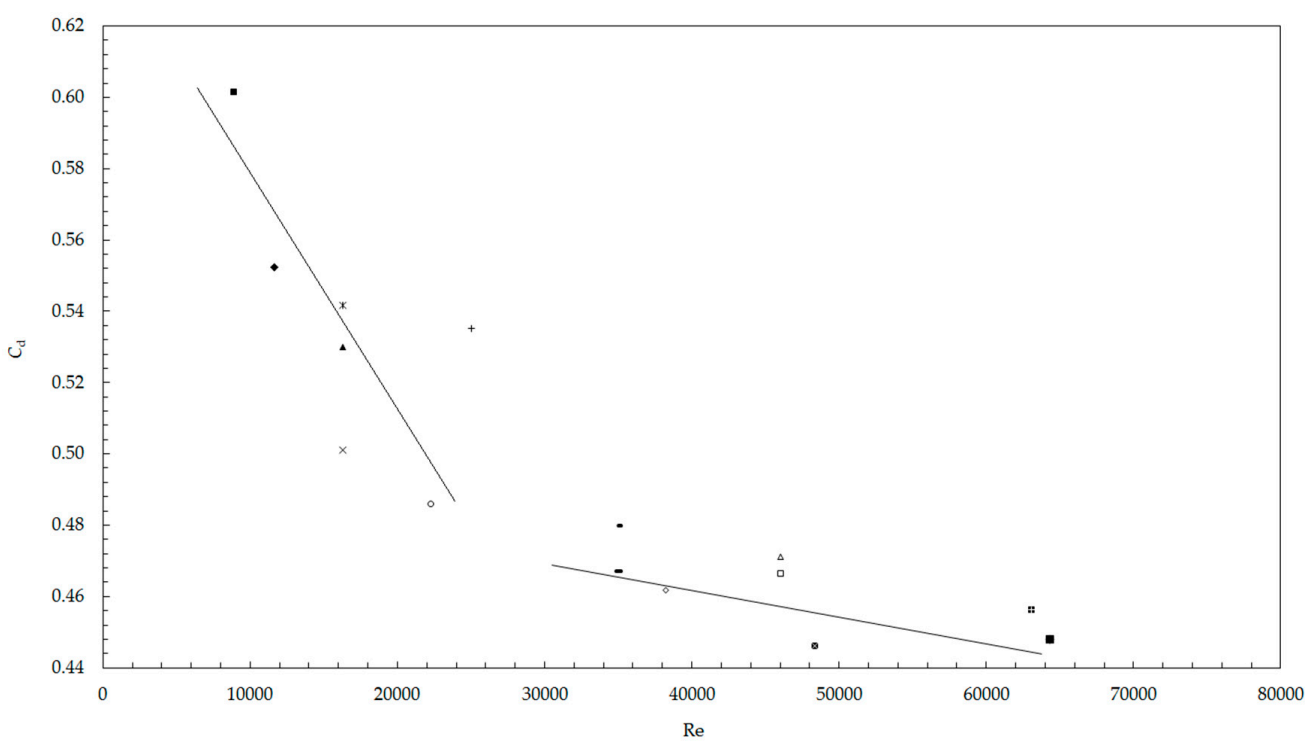

Figure 5. Discharge coefficients $\left(C_{\mathrm{d}}\right)$ versus Re, Series 1 .

To make explicit the functional relation between the discharge coefficient and the parameters on which it depends, $a / h$ and $b / a$, for $\theta=63.4^{\circ}$, a multiple regression was performed considering the values of the experimental variables $(a, b, h$, and $Q$ ) related to the 15 tests summarized in Table 1 . To eliminate the scale effects due to the viscosity and to the surface tension [14], we considered, on the basis of the indications given by Figure 5, only the flow cases characterized by $\operatorname{Re}>2.3 \times 10^{4}$, therefore with $a \geq 4.0 \mathrm{~cm}$ (eight tests).

The following relationship was obtained:

$$
C_{\mathrm{d}}=0.393 \cdot\left(\frac{a}{h}\right)^{-0.269} \cdot\left(\frac{b}{a}\right)^{0.042}
$$

valid for $\theta=1.11 \mathrm{rad}, a \geq 4.0$ and in the range of $0.30 \leq a / h \leq 0.61$ and $1.15 \leq b / \mathrm{a} \leq 3.55$, with determination coefficient $R^{2}=0.927$, maximum percent error $\mathrm{e}_{\max }=3.6 \%$, and average percent error $\mathrm{e}_{\text {average }}=1.3 \%$.

Figure 6 shows the values of the discharge coefficients as a function of the relative opening $a / h$ for the weir inclination angle $\theta=56.3^{\circ}, 63.4^{\circ}$, and $90^{\circ}$, for the aspect ratio $b / a=1.15-2.84$ with $a \geq 5.0 \mathrm{~cm}$.

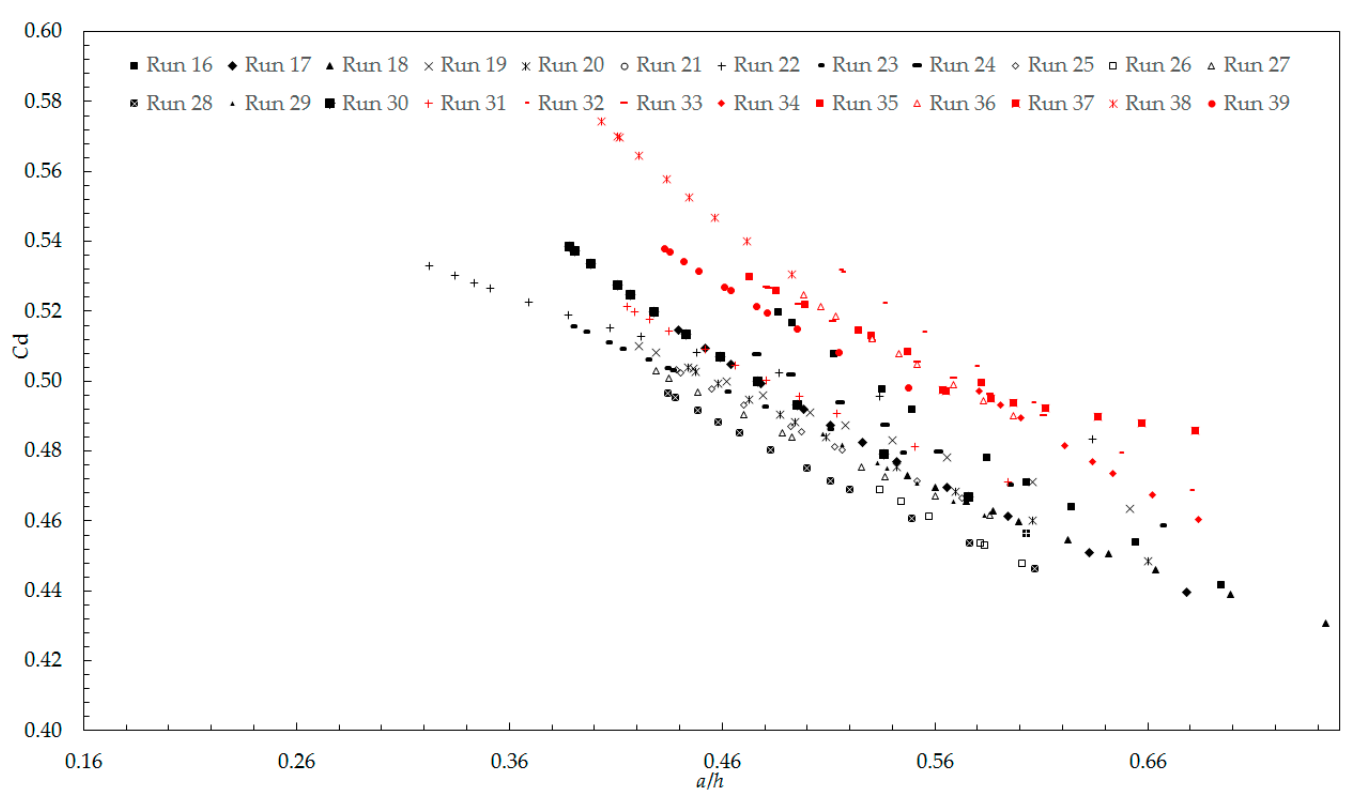

Figure 6. Discharge coefficients $\left(C_{\mathrm{d}}\right)$ versus $a / h$, Series 2 . 
A multiple regression was performed considering the values of the experimental variables related to the 24 tests summarized in Table 2.

The following relationship was obtained:

$$
C_{\mathrm{d}}=0.398 \cdot\left(\frac{a}{h}\right)^{-0.288} \cdot(\theta)^{0.146}
$$

valid for $0.98 \mathrm{rad} \leq \theta \leq 1.57 \mathrm{rad}$ and $a \geq 5.0$ and in the range of $0.32 \leq a / h \leq 0.75$ and $1.15 \leq b / \mathrm{a} \leq 2.84$, with determination coefficient $\mathrm{R}^{2}=0.870$, maximum percent error $\mathrm{e}_{\max }=3.8 \%$, and average percent error $\mathrm{e}_{\text {average }}=1.0 \%$.

Figure 7 shows the values of the discharge coefficients as a function of the relative opening $a / h$ for the weir inclination angle $\theta=45.0^{\circ}, 63.4^{\circ}$, and $90^{\circ}$, for the aspect ratio $b / a=1.23-2.84$ and taking into account only the openings $a \geq 5.0 \mathrm{~cm}$.

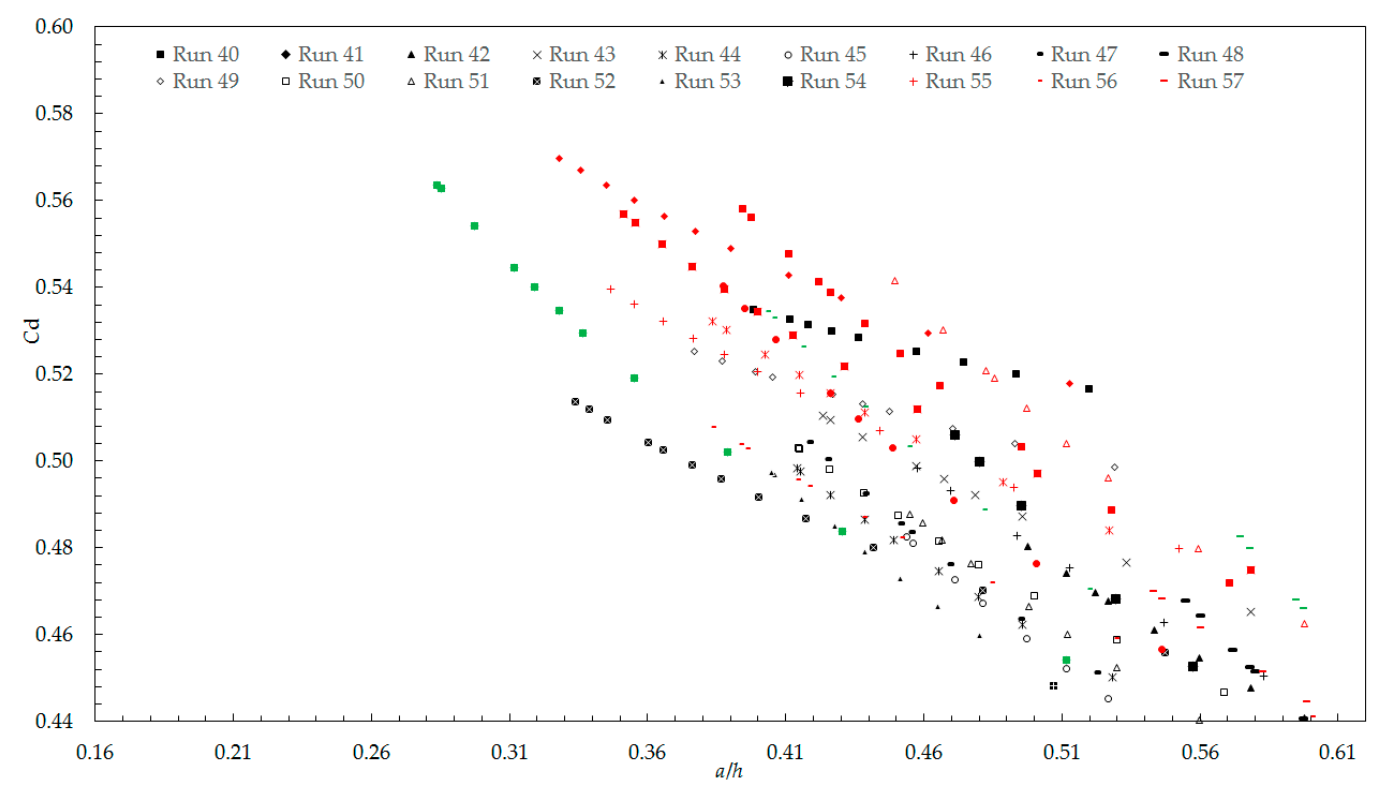

Figure 7. Discharge coefficients $\left(C_{\mathrm{d}}\right)$ versus $a / h$, Series 3 .

A multiple regression was performed considering the values of the experimental variables related to the 27 tests summarized in Table 3 .

The following relationship was obtained:

$$
C_{\mathrm{d}}=0.390 \cdot\left(\frac{a}{h}\right)^{-0.297} \cdot(\theta)^{0.056}
$$

valid for $0.78 \mathrm{rad} \leq \theta \leq 1.57 \mathrm{rad}$ and $a \geq 5.0$ and in the range of $0.30 \leq a / h \leq 0.60$ and $1.23 \leq b / \mathrm{a} \leq 2.84$, with determination coefficient $R^{2}=0.73$, maximum percent error $\mathrm{e}_{\max }=9.6 \%$, and average percent error $\mathrm{e}_{\text {average }}=2.8 \%$.

Comparison of the experimental values with the numerical results and the values given by Equation (20) of the discharge coefficients $\left(C_{d}\right)$ for the 27 runs of Series 3, are shown in Figure 8, while Figure 9 illustrates a comparison of the numerical values of the discharge coefficients $\left(C_{\mathrm{d} \text { num }}\right)$ versus the experimental values of the discharge coefficients $\left(C_{\mathrm{d} \text { exp }}\right)$. By looking at the figures it is clear that the numerical simulation can be considered as an alternative approach to calculate the values of $C_{\mathrm{d}}$, in particular in the cases in which performing laboratory tests is more difficult. 


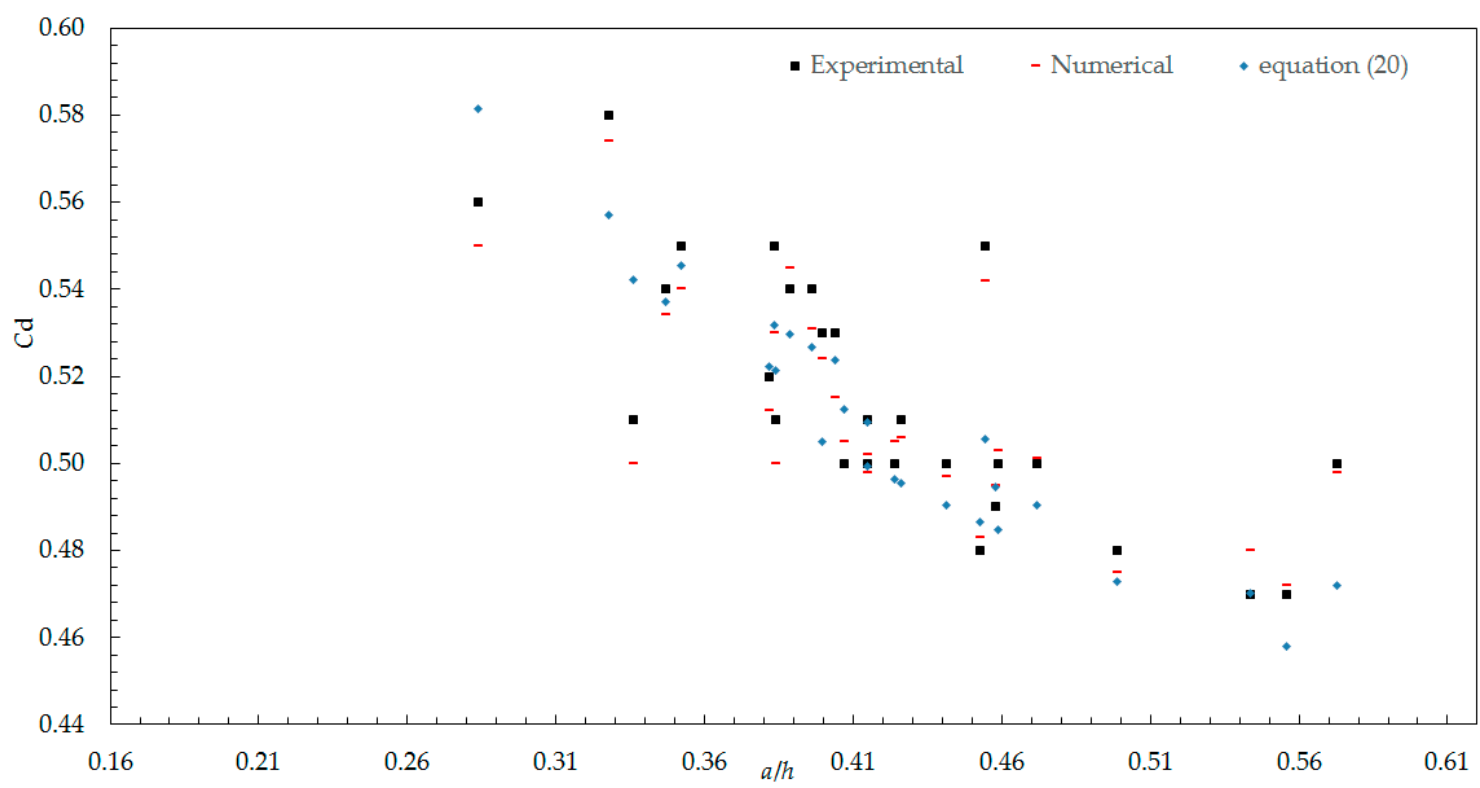

Figure 8. Comparison of experimental, numerical and values given by Equation (20) of the discharge coefficients $\left(C_{d}\right)$, Series 3 .

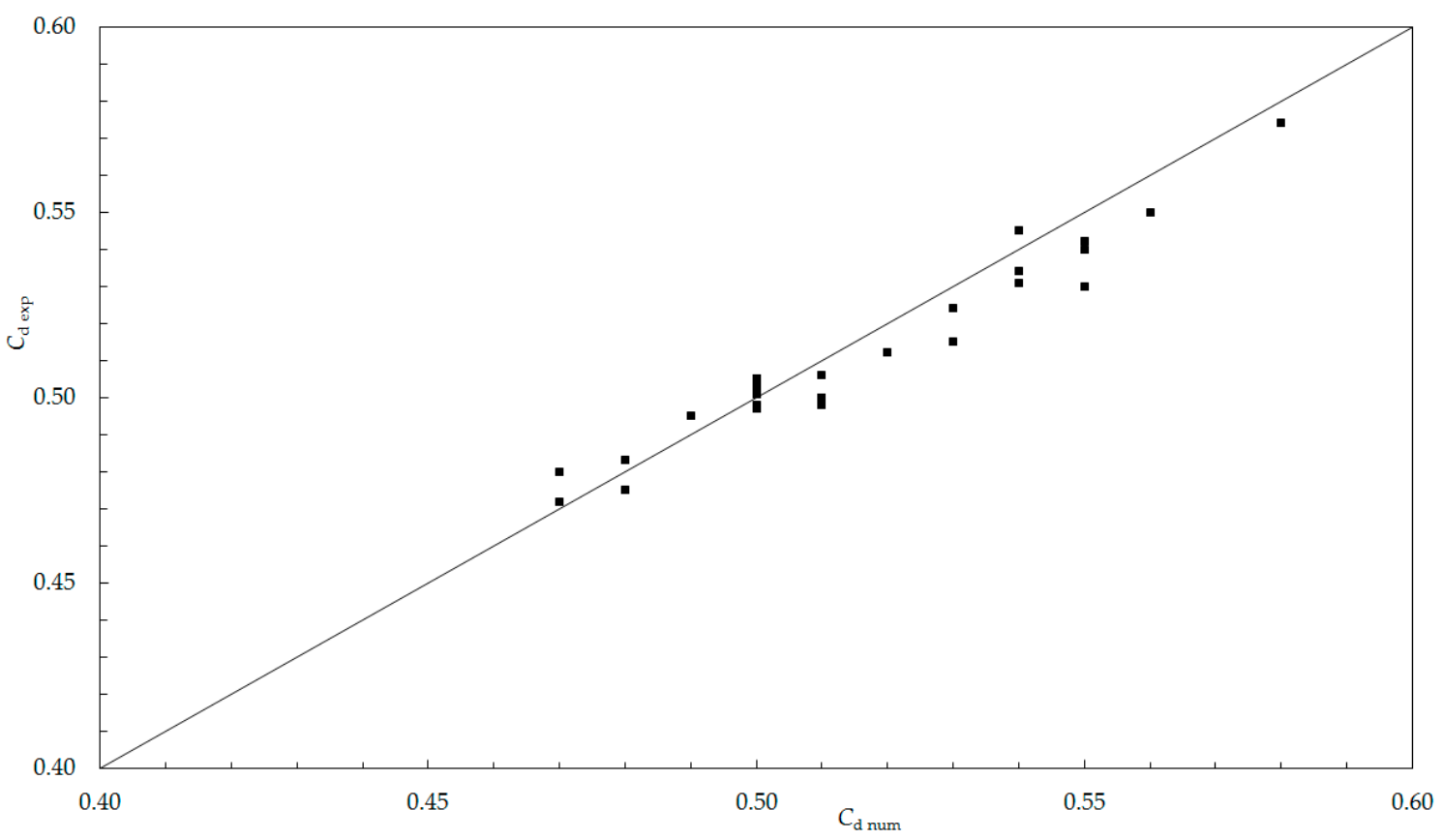

Figure 9. Numerical vs. experimental discharge coefficients of $C_{\mathrm{d}}$, Series 3 .

Figure 10a,b shows, for the Run 40 (Table 3), a comparison between numerical results and values given by Equation (12) of [5], the axial bottom pressure head $H_{\mathrm{p}}$ along the channel upstream from the gate, as a function of the dimensionless location $\mathrm{X}=x / \mathrm{a}$. Figure $10 \mathrm{~b}$ shows a comparison between numerical and values given by the Equation (13) in [5] of the normalized gate pressure distribution $\gamma(Z)$ as a function of dimensionless depth $Z$. 

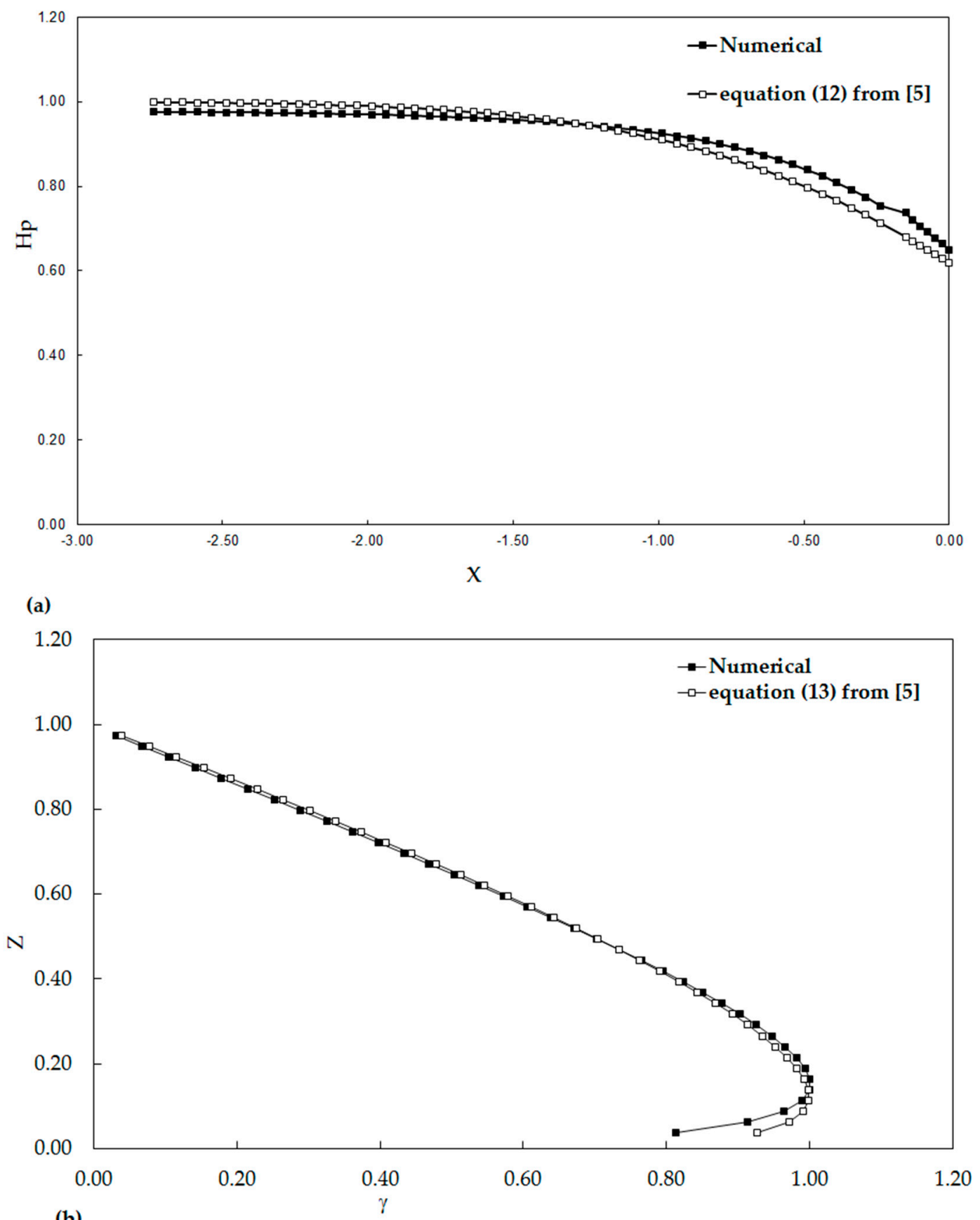

(b)

Figure 10. (a) Bottom pressure distribution comparison with Equation (12) given by [5] and (b) gate pressure distribution comparison with the Equation (13) given by [5].

Figure 11 shows, for the case with angle $\theta$ of $90^{\circ}$, channel width $b$ of $142 \mathrm{~mm}$ and gate opening $a$ equal to $50 \mathrm{~mm}$, a visual comparison between the experimental view and the numerical simulation of the symmetrical oblique waves located downstream from the gate. In particular Figure 11a shows the experimental observation of the waves, while Figure $11 \mathrm{~b}$ shows the simulated numerical field (which is only the right side of Figure 11a). The fluid field obtained numerically (Figure 11b) is colored with the values of fluid pressure. It can be noticed how the symmetrical wave downstream from the gate is well represented. 

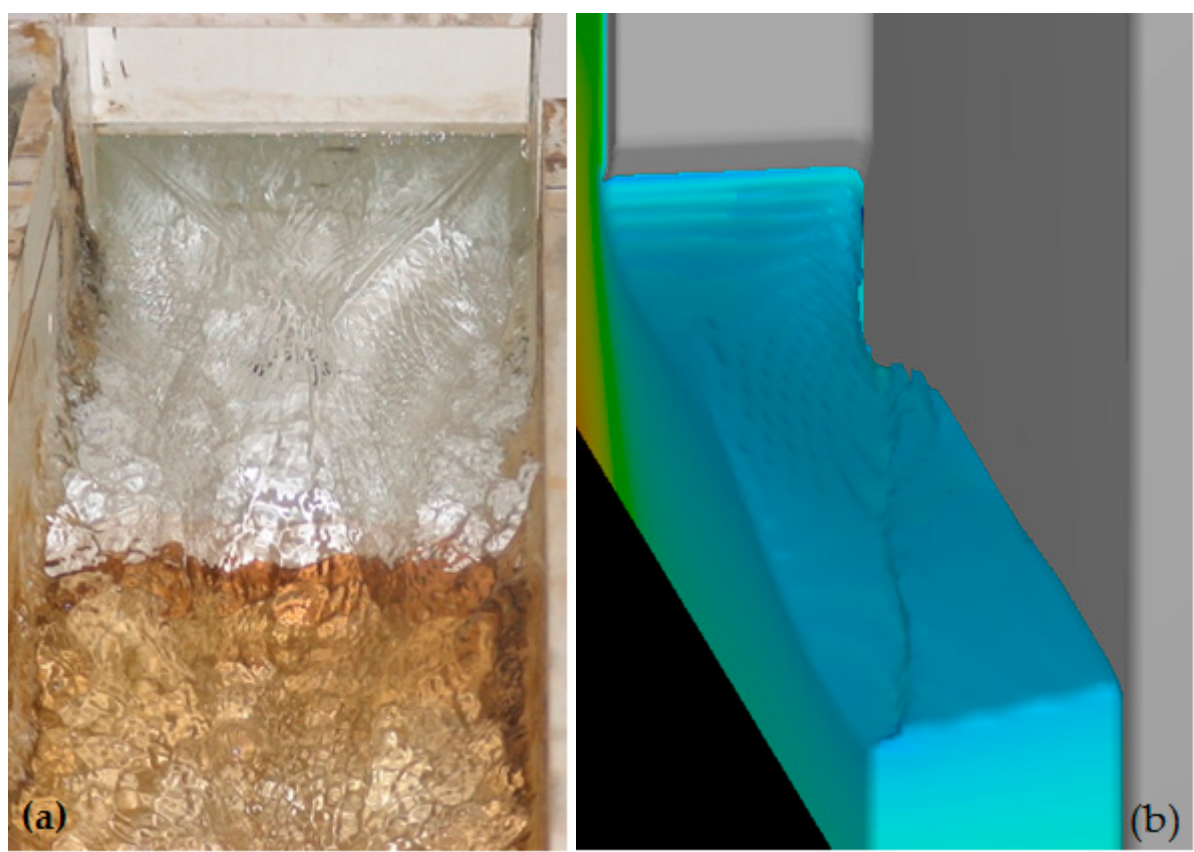

Figure 11. Symmetrical oblique waves downstream from the gate: (a) experimental and (b) numerical.

\section{Conclusions}

In the present work laboratory experiments of discharge coefficients in the case of a gate set on the upstream wall of a weir at different inclination of the wall, allow us to identify the minimum value of the gate opening above which the scale effect due to viscosity is negligible. In this work, the underflow of a sluice gate in weir was analyzed and the effect of the gate slope and the side contraction was considered.

Based on multiple regression, three expressions were found, relating the discharge coefficient with different parameters that characterized the phenomenon at hand.

The first expression (Equation (18)), with a broad-crested weir, was valid only for $\theta=63.4^{\circ}$ and in the range of $0.30 \leq a / h \leq 0.61$ and $1.15 \leq b / a \leq 3.55$.

The second expression (Equation (19)), with a broad-crested weir, was valid for $56.3^{\circ} \leq \theta \leq 90^{\circ}$ and $a \geq 5.0 \mathrm{~cm}$ and in the range of $0.32 \leq a / h \leq 0.75$ and $1.15 \leq b / a \leq 2.84$, and the last expression (Equation (19)), without a broad-crested weir, was valid for $45^{\circ} \leq \theta \leq 90^{\circ}$ and $\mathrm{a} \geq 5.0 \mathrm{~cm}$ and in the range of $0.30 \leq a / h \leq 0.60$ and $1.23 \leq b / a \leq 2.84$.

Our results may provide useful suggestions for those involved in sluice gate construction and management.

Furthermore 27 numerical simulations were carried out by means of the Reynolds-averaged Navier-Stokes equations to take into account the three-dimensionality of the phenomenon. The comparison between the experimental and numerical results revealed that the numerical code using the $\mathrm{k}-\varepsilon$ model in conjunction with the VOF method to track the free surface were sufficiently good to calculate the discharge coefficients, the bottom pressure head along the channel, and the gate axial distribution. The numerical model was also able to describe the oblique waves downstream from the gate showing that the proposed three-dimensional numerical procedure is a favorable option to correctly reproduce the phenomenon.

Author Contributions: A.L. and F.C. contributed in the design, performing, and result analysis of the laboratory tests; A.D. finalized the paper draft; G.A. and A.L. carried out the numerical simulations. All authors have read and agreed to the published version of the manuscript.

Funding: This research received no external funding.

Acknowledgments: The authors wish to thank Antonio Miglio for his contribution in performing the tests and in carrying out dimensional analysis. 
Conflicts of Interest: The authors declare no conflict of interest.

\section{References}

1. Sinniger, R.; Hager, W.H. Constructions Hydrauliques. Ecoulements Stationnaires; Presses Polytechniques Romandes; Traité de Génie Civil de l'Ecole polytechniques fédérale de Lausanne: Lausanne, Switzerland, 1988; Volume 15.

2. Montes, J.S. Irrotational flow and real fluid effects under planar sluice gates. J. Hydraul. Eng. 1997, 123, 219-232. [CrossRef]

3. Gentilini, B. Efflusso dalle luci soggiacenti alle paratoie piane inclinate e a settore. L'Energia Elettrica 1941, 18, 361-380.

4. Rajaratnam, N.; Subramanya, K. Flow equation for the sluice gate. J. Irrig. Drain. Eng. 1967, 93, 167-186.

5. Roth, A.; Hager, W.H. Underflow of standard sluice gate. Exp. Fluids 1999, 27, 339-350. [CrossRef]

6. Rajaratnam, N. Free flow immediately below sluice gates. J. Hydraul. Div. ASCE 1977, 103, 345-351.

7. Kim, D.G. Contraction and discharge coefficient of free flow past a sluice gate. In Proceedings of the Korea Water Resources Association Conference; Korea Water Resources Association: Seoul, Korea, 2005; pp. 1281-1282.

8. Kim, D.G. Numerical Analysis of Free Flow Past a Sluice Gate. KSCE J. Civ. Eng. 2007, 11, 127-132. [CrossRef]

9. Akoz, M.S.; Kirkgoz, M.S.; Oner, A.A. Experimental and numerical modeling of a sluice gate flow. J. Hydraul. Res. 2009, 47, 167-176. [CrossRef]

10. Oskuyi, N.; Salmasi, F. Vertical Sluice Gate Discharge Coefficient. J. Civ. Eng. Urban. 2012, 2, $108-114$.

11. Raju, R. Scale Effects in Analysis of Discharge Characteristics of Weir and Sluice Gates; Kobus: Esslingen am Neckar, Germany, 1984.

12. Lauria, A. Efflusso da luce di fondo di una traversa per laminazione delle piene. Analisi Sperimentale e Modellazione Numerica 3D. Ph.D. Thesis, Università della Calabria, Rende, Italy, 2008.

13. Calomino, F.; Lauria, A.; Miglio, A.; Palma, G. Discharge coefficients for sluice gates in weir. In Proceedings of the Congress-International Association for Hydraulic Research, Venice, Italy, 1-6 July 2007.

14. Calomino, F.; Lauria, A.; Miglio, A.; Palma, G. Determinazione sperimentale dei coefficienti d'efflusso da paratoie con diversa inclinazione per casse d'espansione. In Proceedings of the $30^{\circ}$ Corso di aggiornamento in Tecniche per la difesa dall'inquinamento, Guardia Piemontese Terme (CS), Cosenza, Italy, June 2009; pp. 261-290.

15. Calomino, F.; Lauria, A. 3-D Underflow of a Sluice Gate at a Channel Inlet; Experimental Results and CFD Simulations. J. Civ. Eng. Urban. 2014, 4, 501-508.

16. Aristodemo, F.; Lauria, A.; Tripepi, G.; Rivera-Velasquéz, M.F.; Fallico, C. Smoothing of Slug Tests for Laboratory Scale Aquifer Assessment-A Comparison among Different Porous Media. Water 2018, 11, 1569. [CrossRef]

17. Calomino, F.; Alfonsi, G.; Gaudio, R.; D’Ippolito, A.; Lauria, A.; Tafarojnoruz, A.; Artese, S. Experimental and numerical study of free-surface flows in a corrugated pipe. Water 2018, 10, 638. [CrossRef]

18. D'Ippolito, A.; Lauria, A.; Alfonsi, G.; Calomino, F. Investigation of flow resistance exerted by rigid emergent vegetation in open channel. Acta Geophys. 2019, 67, 971-986. [CrossRef]

19. Lauria, A.; Alfonsi, G. Numerical investigation of ski jump hydraulics. J. Hydraul. Eng. ASCE 2020, in press. [CrossRef]

20. Wilcox, D.C. Turbulence Modeling for CFD; DCW Industries: La Cañada, CA, USA, 1998.

21. Launder, B.E.; Spalding, D.B. The numerical computation of turbulent flows. Comput. Methods Appl. Mech. Eng. 1974, 3, 269-289. [CrossRef]

22. FLOW SCIENCE. FLOW-3D User Manual: Excellence in Flow Modeling, Software Version 9.1; Flow Science, Inc.: Santa Fe, NM, USA, 2004.

23. Alfonsi, G.; Lauria, A.; Primavera, L. Recent reults from analysis of flow structures and energy modes induced by viscous wave around a surface-piercing cylinder. Math. Probl. Eng. 2017. [CrossRef]

24. Alfonsi, G.; Lauria, A.; Primavera, L. On evaluation of wave forces and runups on cylindrical obstacles. J. Flow Visual. Image Process. 2013, 20, 269-291. [CrossRef]

25. Hirt, C.W.; Nichols, B.D. Volume of fluid (VOF) method for the dynamics of free boundaries. J. Comput. Phys. 1981, 39, 201-225. [CrossRef] 
26. Alfonsi, G.; Lauria, A.; Primavera, L. Proper orthogonal flow modes in the viscous-fluid wave-diffraction case. J. Flow Visual. Image Process. 2013, 20, 227-241. [CrossRef]

27. Alfonsi, G.; Lauria, A.; Primavera, L. The field of flow structures generated by a wave of viscous fluid around vertical circular cylinder piercing the free surface. Procedia Eng. 2015, 116, 103-110. [CrossRef]

28. Alfonsi, G.; Lauria, A.; Primavera, L. A study of the vortical structures past the lower portion of the Ahmed car model. J. Flow Visual. Image Process. 2013, 19, 81-95. [CrossRef]

29. Novak, P.; Moffat, A.I.B.; Nalluri, C.; Narayanan, R. Hydraulic Structures; E \& FN Spon: London, UK, 1996.

(C) 2020 by the authors. Licensee MDPI, Basel, Switzerland. This article is an open access article distributed under the terms and conditions of the Creative Commons Attribution (CC BY) license (http://creativecommons.org/licenses/by/4.0/). 